\title{
Social justice: A qualitative and quantitative study of representations of social justice in children of primary education
}

\author{
Almudena Juanes García ${ }^{1}$, Vanesa Sainz López ${ }^{1}$, Tatiana García Vélez ${ }^{1}$ and Antonio \\ Maldonado Rico y Liliana Jacott Jiménez ${ }^{1 \mathrm{a}}$ \\ ${ }^{1}$ Departamento Interfacultativo de Psicología Evolutiva y de la Educación. Facultad de Formación de \\ Profesorado y Educación. Universidad Autónoma de Madrid, España. Universidad Autónoma de \\ Madrid, c/ Francisco Tomás y Valiente, 3. Ciudad Universitaria de Cantoblanco, 28049, Madrid, \\ Spain.
}

\begin{abstract}
In order to study children's conceptions of primary education about Social Justice, we have applied a questionnaire and an interview, based on dilemmas of different situations on the educative and social context. Participants were 4th and 6th grade primary education students from five schools of the Community of Madrid. We compared the responses of the students by grade, gender and school type (schools promoters of social justice vs. standard schools). The results show differences between grade or gender, in a different way in questionnaire and interview. In further analysis we are try to compare the responses of the students enrolled in schools promoters of social justice with those of students enrolled in standard schools.
\end{abstract}

Keywords. Social Justice; primary students; dilemmas; gender; grade; school type.

\section{Introduction}

In the last decade, there is an increasing emphasis of social justice as an important theme in education. The first theoretical conceptualization of social justice can be found in Rawls' Theory of Justice. Framed in the liberal tradition of the philosophy of law, Rawls comes to propose social justice as the goal of distributive justice.

In our opinion, under the concept of social justice we can find several visions of society and justice that are radically different. Thus, the concept of social justice cannot have a single meaning as it is used for different purposes.

\footnotetext{
a Corresponding author: almudena.juanes@inv.uam.es
} 
From our point of view, social justice is seen as a dynamic project, which should always be subject to reflection and improvement. We believe that this is how education should also be taken today, as always subject to change and

constantly review project adapted to a culture and a certain time.

Our research group agrees with a 3R's model of Social Justice based in Fraser [3] because we think that allows analyzing different dimensions in Education [7, 4]. The three dimensions are:

- Redistribution [8; 9] of educative resources.

- Recognition [2] as respect to the differences and inequalities in education, and active promotion of them.

- Representation [3] (also called participation) as the full participation in social life, especially for those who have been systematically excluded on the basis of gender, physical or mental ability, sexual orientation or other characteristics of group.

These three concepts are not independent, but must be considered as interconnected in the struggle for social justice.

We believe that it is essential to explore conceptions of children, for promote a change towards a quality education, that incorporates the ideas of the children in relation into the social justice, not only in educational questions, but also social and political. In this context, we are trying to study and analyze, the conceptions of Social Justice in Primary education students.

\subsection{Objectives}

We have three main objectives:

- a) Construction and validation of an interview and a questionnaire to know the conceptions of three dimensions of Social Justice in primary students.

- b) Analysis of developmental trends in students of 4th and 6th grade, and gender differences.

- c) Comparison between these conceptions in students of schools promoters of social justice students of standard schools.

We expect to find differences in student's conceptions of Social Justice (and their constituent's dimension) by grade, gender and school type (less or more promoters of Social Justice):

Respect grade, we expect more complex conceptions in students of 6th grade, versus 4th grade students for their obvious development.

In relation to gender, we expect more elaborated concepts in girls than boys, according to previous studies about prosocial thinking $[6 ; 1 ; 5]$, that show that girls are more prosocial in her behavior, thinking ad affective responses.

And finally we expect less social justice responses in less social justice promoters schools versus high social justice schools. We think that students of schools promoters of social justice have a major knowledge of the ways of solving the situations, by means of nearest strategies to the social justice.

\section{METHOD}

The study is divided in two phases. In the first phase, we did an exploratory study applying in order to evaluate the new questionnaires and interviews that were designed. These questionnaires an interviews, were applied to a sample of 4th and 6th grade students of primary education, in a school of the Community of Madrid., in order to adapt the main 
general procedure. The 4th grade students were 10 years old and the 6th grade students were 12 years old.

In the second phase, we collect data from 480 Spanish children (240 from 4th grade and 240 from 6th grade) applying questionnaires and interviews in four schools of the Community of Madrid. Two schools were considered by experts as promoters of school justice and two schools were considered as less promoters of social justice.

Both questionnaire and interview consists in asking about specific social justice dilemmas that are familiar to primary students. These dilemmas we selected from a previous questionnaire designed to analyze Social Justice conceptions in group (multidisciplinary experts in Social Justice) for high school students and teachers, further validation and pilot study.

The final interview was applied by a researcher with experience in that field. The interview adopts a semi structured format in which six dilemmas were presented. The participants were asked to suggest their opinion about the solution of each of dilemmas, the interview were applied to 80 children, from 4 th and 6 th grade (50\% girls).

In the questionnaire, the dilemmas were presented with three possible alternatives of response. The three alternatives were arranged in social justice dimension: one was considered as high Social Justice, another as low Social Justice and the third alternative was in an intermediate level of Social Justice. In the Social Justice interview the children were facing only the dilemmas without suggesting explicit alternatives, and the students must indicate her or his solution to the above dilemma.

400 students from 4th and 6th grade were participants in this questionnaire. The gender, age and school type of participants were uses as independent variables.

\section{Results}

In order to analyze the results, in the interview, we calculated the number of children who show different types of answers (a clear reflection toward Social Justice Issues) On the other hand, in the questionnaire, we calculated a Global Index for Social Justice (and 3 different index for each three dimension: Redistribution (Rd), Recognition (Rc) and Representation (Rp), that goes from low Social Justice to high Social Justice.

Both questionnaire and interview responses were analyzed quantitatively, by IBM/ SPSS v.22.

Previously, the responses of interview were analyzed qualitatively, after transcription and coding of response categories which are based on the continuous (from the least to the most socially just responses).

The results of exploratory study reflect several differences with respect grade or with respect gender. But we found different results in questionnaire and interview data.

In the interview, we found that 6 th grade students have a more elaborated conceptions of Social Justice than 4th grade students, as we expected $(p<0,001)$.

With respect gender, although girls tend to have more elaborated conceptions of Social Justice; these differences are not statistically significant.

However, in the questionnaire, we found the opposite trend: there are differences with respect gender but not with respect grade.

We show below an example of the difference in responses between 4th and 6th students to one of the interview questions. In this case, the question is the next (translated from Spanish):

"At your school there are several students who rarely participate in activities outside the classroom.

What would you do to encourage them to participate?"

a. Ask teachers to organize activities that help them to participate more. 
b. Propose activities with my friends.

c. Talk to them and try and think of other ways of participating.

In the questionnaire, the students read these three response options and must choose one.

In the interview, we tell the dilemma to children, but we don't give them these three responses. Children have to give us their own solution to the dilemma. Children's answers in the interview were recorded.

Adrián, of 4th grade, answer the following:

"Teachers could talk to them to propose an activity."

He leaves the solution on teachers but does nothing by himself to help students to participate. However, Daniel of 6th grade, answer the following:

"But why they don't play or don't let them play?(...) I first ask them why they do not play, because maybe it's their way of having (...) I would ask them why they do not participate and then if they want to participate, I would tell the others to let them play. "

Daniel thinks not only to help them to participate with him and his friends, but also thinks that it is important to know the reason for not participating, while respecting their decision.

On the other hand, at present, we are comparing responses of students enrolled in social justice schools versus no social justice schools.

We are analyzing the responses to each dilemma also in qualitative categories in order to describe different levels of Social Justice thinking in children

Finally, it is important indicate that contrary to the history of social justice theories that initially focus on Redistribution and later on the other dimensions, the Redistribution dilemmas were the most difficult to understand by children. In all cases, children show a better understanding of Representation dilemmas, than Recognition and Redistribution ones. This trend is the opposite of teachers, because they show a higher tendency to focus on Redistribution.

\section{Discussion}

Our results show that we should pay more attention to differences between data obtained from the questionnaire and interview. We think that it is important take into account the results that indicated that the Redistribution dilemmas were the most difficult to understand for children. We think that this may be due to two main reasons: Children usually don't take part of the redistribution decisions, things related to economic resources are not so close from them. However, representation is very common in school, for example with group class.

In addition, Redistribution is a dimension that is more difficult for children understanding. For primary students is harder to think about more abstract issues such as poverty or money recourses, because this is a preliminary step to formal operations.

Our study represents a first approach to the conceptions of social justice for children in primary students but it is necessary to study more deeply the conceptions of social justice of children coming from different contexts.

At the present, we are analyzing the results obtained in another schools, and we are comparing the responses of the students enrolled in schools promoters of social justice with those of the students enrolled in standard schools. 


\section{References}

1. Eisenberg, N. Prosocial Development. In W. Damon, R.M. Lerner, and N. Eisenberg (Eds.), Handbook of Child Psychology. Social, Emotional, and Personality Development (pp. 646-718) Hoboken, NJ: John Wiley and Sons, (2006).

2. Fraser, N., \& Honneth, A. Redistribución o reconocimiento? Un debate filosófico, Madrid: Ediciones Morata S. L., (2006).

3. Fraser, N. Escalas de justicia. Barcelona: Herder, (2008).

4. Jacott, L., \& Maldonado, A. Social Justice and citizenship education. CiCe's 14th Annual Conference: Creating Citizenship Communities: Local, National and Global. York University, paper, (2012).

5. Jaffe, S., \& Hayde, J. S. Gender differences in moral orientation: A metanalysis. Psychological Bulletin, 126, 703-726, (2000).

6. Metzger, A., \& Smetana, J. G. Social Cognitive Development and Adolescent Civic Engagement. In L. R. Sherrod, J. Torney-Purta \& C. A. Flanagan (Eds.), Handbook of Research on Civic Engagement in Youth (pp. 221-248) Hoboken, NJ: John Wiley and Sons, (2010).

7. Murillo, F. J., \& Hernández-Castilla, R. Hacia un concepto de justicia social. Revista Iberoamericana sobre Calidad, Eficacia y Cambio en Educación 9 (4), 8-23, (2011).

8. Rawls, J. A theory of justice. Cambridge, MA: Harvard University Press, (1971).

9. Sen, A. The Idea of Justice. Cambridge: Harvard University Press and Allen Lane, (2009). 